\title{
Patient Height may Predict the Length of the Anterior Cruciate Ligament: A Magnetic Resonance Imaging Study
}

\author{
Ludwig Andribert Powantia Pontoh, M.D., Ph.D., Ahmad Jabir Rahyussalim, M.D., Ph.D., \\ and Jessica Fiolin, M.D.
}

\begin{abstract}
Purpose: The purpose of this study was to measure the length and width of anterior cruciate ligament (ACL) tibial footprint using magnetic resonance imaging (MRI) and to evaluate correlation between patients' weight and height with the tibial footprint size. Methods: In total, 207 eligible patients underwent MRI scanning from June 2018 to June 2020. One hundred seventeen knees from patients aged 18 to 40 years old with intact ACL were included in this study. Data of weight, height, body mass index (BMI) from physical examination and tibial footprint length and width from MRI were obtained. Relationship of ACL tibial footprint length $<14 \mathrm{~mm}$ and association between ACL tibial footprint sizes of MRI with height, weight, and BMI were analyzed. Results: The ACL tibial footprint length and width were, respectively, $11.9 \pm 1.8 \mathrm{~mm}$ and $10 \pm 1.5 \mathrm{~mm}$. Proportion of ACL footprint $<14 \mathrm{~mm}$ in length was $89.7 \%$. Patient height $\geq 170 \mathrm{~cm}$ was the best predictor of ACL tibial footprint length $<14 \mathrm{~mm}(P=.025)$. There was a statistically significant relationship between the height of the patients and the length of the ACL tibial footprint. The length of the ACL tibial footprint could be predicted by the formula: length $=-7.362+11.48 \times$ (height in meters). Conclusion: The height of the patients may predict the length of the ACL tibial footprint. Although patient's age, sex, and BMI correlate poorly with ACL tibial footprint width, there was no correlation between patient's weight and ACL tibial footprint size. Clinical Relevance: Before ACL reconstruction surgery, an estimation of ACL tibial footprint size might aid in the graft harvesting preparation.
\end{abstract}

$\mathbf{T}$ he increased number of anterior cruciate ligament (ACL) reconstructions each year has led to more individualized techniques and better outcomes. An

From the Knee Division of Department of Orthopaedic and Traumatology, Fatmawati General Hospital-Faculty of Medicine Universitas Indonesia (L.A.P.P.), Jakarta Selatan, the Spine Division of Department of Orthopaedic and Traumatology, Dr. Cipto Mangunkusumo General Hospital-Faculty of Medicine Universitas Indonesia (A.J.R.), Jakarta Pusat, and the Jakarta Knee, Shoulder and Orthopaedic Sport Clinic, Pondok Indah Hospital (J.F.), Jakarta, Indonesia.

The authors report that they have no conflicts of interest in the authorship and publication of this article. Full ICMJE author disclosure forms are available for this article online, as supplementary material.

Received October 4, 2020; accepted January 21, 2021.

Address correspondence to Ludwig Andribert Powantia Pontoh, MD, PhD, Knee Division of Department of Orthopaedic and Traumatology, Fatmawati General Hospital-Faculty of Medicine Universitas Indonesia, Jl. RS Fatmawati no. 4, Jakarta Selatan, 12430,Indonesia.E-mail: andrepontoh@gmail. com

(C) 2021 THE AUTHORS. Published by Elsevier Inc. on behalf of the Arthroscopy Association of North America. This is an open access article under the CC BY-NC-ND license (http://creativecommons.org/licenses/by-nc-nd/4.0/). 2666-061X/201290

https://doi.org/10.1016/j.asmr.2021.01.012 individualized ACL reconstruction is a surgical procedure that is adjusted to each patient's lifestyle, activity level, and native anatomy that is believed to restore normal knee kinematics. ${ }^{1}$

Recent studies showed that double-bundle ACL reconstruction resulted in better anteroposterior and rotational stability with fewer re-ruptures rate compared to conventional single-bundle procedures. $^{2,3}$ However, it is difficult to preserve a bony bridge between 2 bone tunnels within the native footprints in the tibia caused by the lack of definite surgical landmarks. ${ }^{4,5}$ An approximately $6 \mathrm{~mm}$ diameter of anteromedial bundle and $5 \mathrm{~mm}$ diameter of posterolateral bundle with $2 \mathrm{~mm}$ of bony bridge necessitates a total of $\geq 13 \mathrm{~mm}$ for a successful procedure. $^{6}$

Preoperative knowledge of native ACL insertion sizes obtained would be valuable for better surgical planning. Kopf et al. ${ }^{7}$ reported that when the arthroscopic anteroposterior diameter of the ACL insertion is $<14 \mathrm{~mm}$, a single-bundle ACL reconstruction should be performed instead of a double-bundle procedure. However, measuring the diameter arthroscopically may be difficult. 
Kim et al. ${ }^{8}$ proved that ACL tibial footprint sizes measured on magnetic resonance imaging (MRI) showed strong correlation with its actual sizes.

Several literatures have studied the correlation between patients' weight and height with their tibial ACL insertion sizes throughout the world. ${ }^{7-11}$ The purpose of this study were to measure the length and width of ACL tibial footprint using MRI and to evaluate correlation between patients' weight and height with the tibial footprint size. We hypothesized that there was a correlation between patient's height and weight with the ACL tibial footprint sizes.

\section{Methods}

\section{Participants}

This was a retrospective study of patients with knee pain who were evaluated at the knee and sport clinic of a private hospital and underwent MRI of their knees between June 2018 and June 2020 were included in the present study. All patients were examined by the senior orthopaedic knee consultant in our hospital. The inclusion criteria were (1) age 18 to 40 years and (2) intact ACL, whereas exclusion criteria were as follows: (1) osteoarthritis or osteophytes around tibial insertion of ACL, (2) infection or trauma surround ACL attachment, and (3) multiligament knee injury. Informed consent was obtained from all patients, and this study was approved by the institutional review board of our hospital.

Of 207 eligible patients, 90 were excluded from this study as a result of the above criteria; 73 had torn ACL, 15 had osteophyte around ACL footprint, 2 had a history of previous knee trauma. One hundred seventeen cases were included in this study.

\section{Measurement of ACL Tibial Footprint}

Measurements of the length and width of ACL tibial footprint on MRI were performed by 2 orthopaedic surgeons following the published methods by Kim et al. ${ }^{8}$ and Araujo et al. ${ }^{12}$ The 3.0-T magnet MRI scans were acquired with use of a Magnetom Skyra (Siemens Medical Solutions, Malvern, PA). The image is then imported to Carestream Vue Motion (Carestream Health Inc, Rochester, NY) for analysis. The following protocols were used: proton density-weighted sagittal image (thickness, $3.0 \mathrm{~mm}$; time of repetition, 1,300 milliseconds; time to echo, 15-17 milliseconds), T2weighted sagittal images (thickness, $3.0 \mathrm{~mm}$; time of repetition, 4,000 milliseconds; time to echo, 100-110 milliseconds), and oblique coronal proton densityweighted images (thickness, $3.0 \mathrm{~mm}$; time of repetition, 1,300 milliseconds; time to echo, 15-17 ms).

Measurements were performed twice by 2 different orthopaedic surgeons, and the mean value was recorded. To measure the exact length of tibial insertion site,

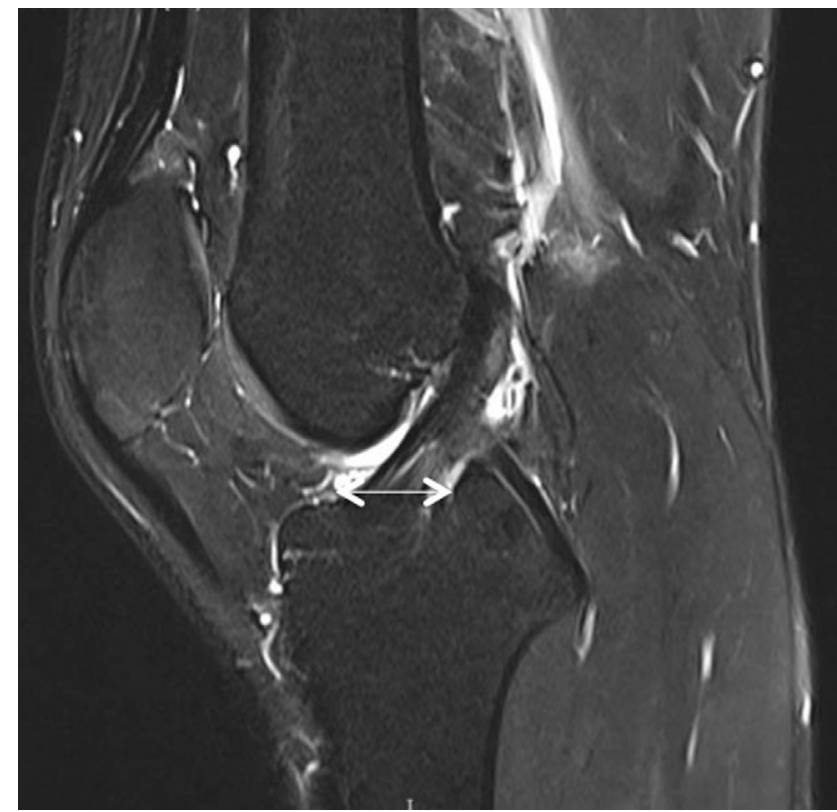

Fig 1. T2 sagittal magnetic resonance imaging scan of left knee with patient in supine position. Measurement of the length (white arrows) of the anterior cruciate ligament tibial footprint on sagittal magnetic resonance imaging.

the clearest sagittal image cut showing both the tibial and femoral insertion sites. The length of ACL tibia footprint was measured as the distance from the most anterior to the most posterior fiber of the ACL tibial attachment site (Fig 1).

To measure the width of ACL tibial footprint, an oblique coronal image best showing the ACL fiber tibial attachment was selected. A line was drawn above the subchondral bone as close as possible to the bone between the most medial and most lateral portions of the ACL fiber tibial attachment. The length of the line was measured as the width of the ACL tibial foot print (Fig 2).

\section{Statistical Analysis}

All data were collected and analyzed using SPSS software version 23 (IBM, Armonk, NY). Descriptive statistics were calculated for all variables. Unpaired $t$ tests were used to compare the differences between gender and physical characteristics. To compare the continuous variables between patients with ACL tibial footprint length $\geq 14 \mathrm{~mm}$, Mann-Whitney testing was performed, and univariable logistic regression was performed to calculate the odds ratio (OR) with a $95 \%$ confidence interval (CI). Multivariable logistic regression was then performed to determine variable that best predicted the presence of ACL tibial footprint length $<14 \mathrm{~mm}$. Cutoff value for strongest predictor was calculated by maximally selected median variable. All significance level was set at $P<.05$. Intraobserver and interobserver reliability of the ACL tibial footprint size 


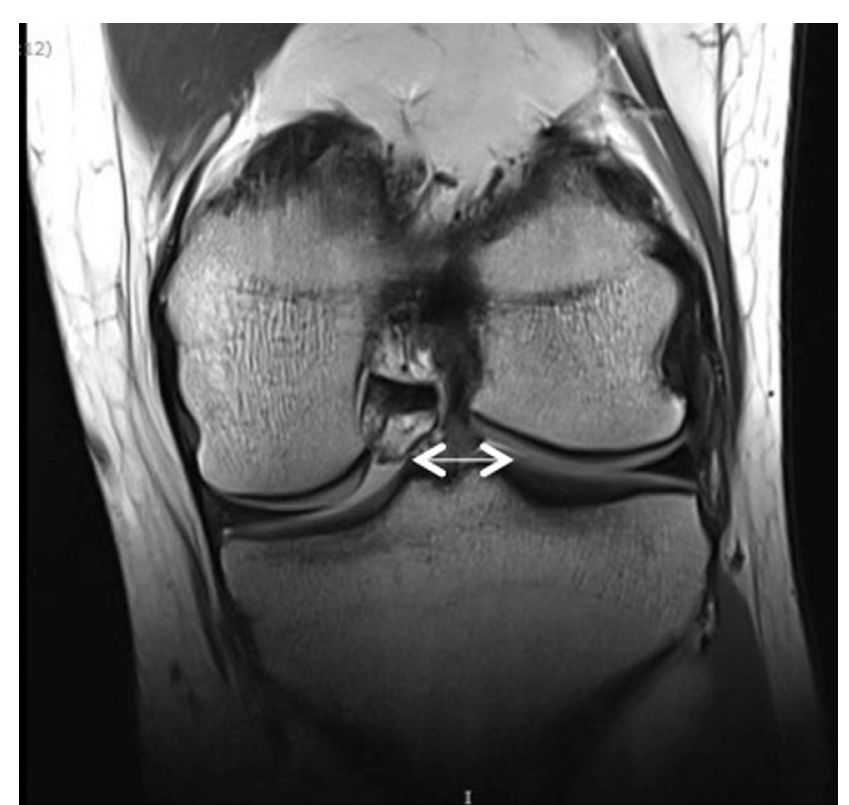

Fig 2. Tl coronal magnetic resonance imaging scan of left knee with patient in supine position. Measurement of the width (white arrows) of the anterior cruciate ligament tibial footprint on oblique coronal magnetic resonance image.

on MRI was analyzed with an intraclass correlation coefficient. The strength of agreement can range from 0 to 1 ( $\geq 0.80$, good; 0.60-0.79, moderate; $\leq 0.59$, poor).

The Pearson rank correlation coefficient was calculated to evaluate the association between the size of
Table 1. Physical Characteristics of the Participants

\begin{tabular}{lccc}
\hline & Height $(\mathrm{cm})$ & Weight $(\mathrm{kg})$ & $\mathrm{BMI}\left(\mathrm{kg} / \mathrm{m}^{2}\right)$ \\
\hline Total & $168.07 \pm 0.1$ & $75.2 \pm 17.3$ & $26.5 \pm 5.17$ \\
Male & $172.44 \pm 0.05$ & $81.66 \pm 15.72$ & $27.36 \pm 4.58$ \\
Female & $159 \pm 0.06$ & $61.76 \pm 11.88$ & $24.68 \pm 5.88$ \\
$P$ value $^{*}$ & $<.0001$ & $<.0001$ & .016 \\
$95 \%$ CI & $14.19-25.60$ & $0.11-0.16$ & $0.52-4.85$ \\
\hline
\end{tabular}

Data were given in mean \pm standard deviation.

BMI, body mass index $\left(\mathrm{kg} / \mathrm{m}^{2}\right)$; CI, confidence interval.

${ }^{*}$ Comparison of values between males and females.

ACL tibial footprint and patient's weight, height, and BMI. The strength of the correlation was indicated by the coefficient -1 to +1 . When the relationship of 1 variable decreases while the other increases, the coefficient is negative but greater than -1 ; when both variables increase, the coefficient is positive but less than 1; and when a relationship is random or nonexistent, the coefficients are nearly 0. Simple linear regression was used to estimate the association between patients' height and weight with ACL tibial footprint size. Multiple linear regression equations were used to predict the size of ACL tibial footprint based on patients' height.

\section{Results}

In total, 117 cases (79 men, 38 women) were enrolled in this study. The participants had a mean age of 31.62 \pm 5.71 (range, $19-40$ years), a mean height of $168.07 \pm$
Fig 3. Distribution of anterior cruciate ligament tibial footprint length in the study population. Tibial footprint length of $13 \mathrm{~mm}$, $12 \mathrm{~mm}$, and $11 \mathrm{~mm}$, respectively, are the most common group length in the population. TFPL, tibial footprint length.

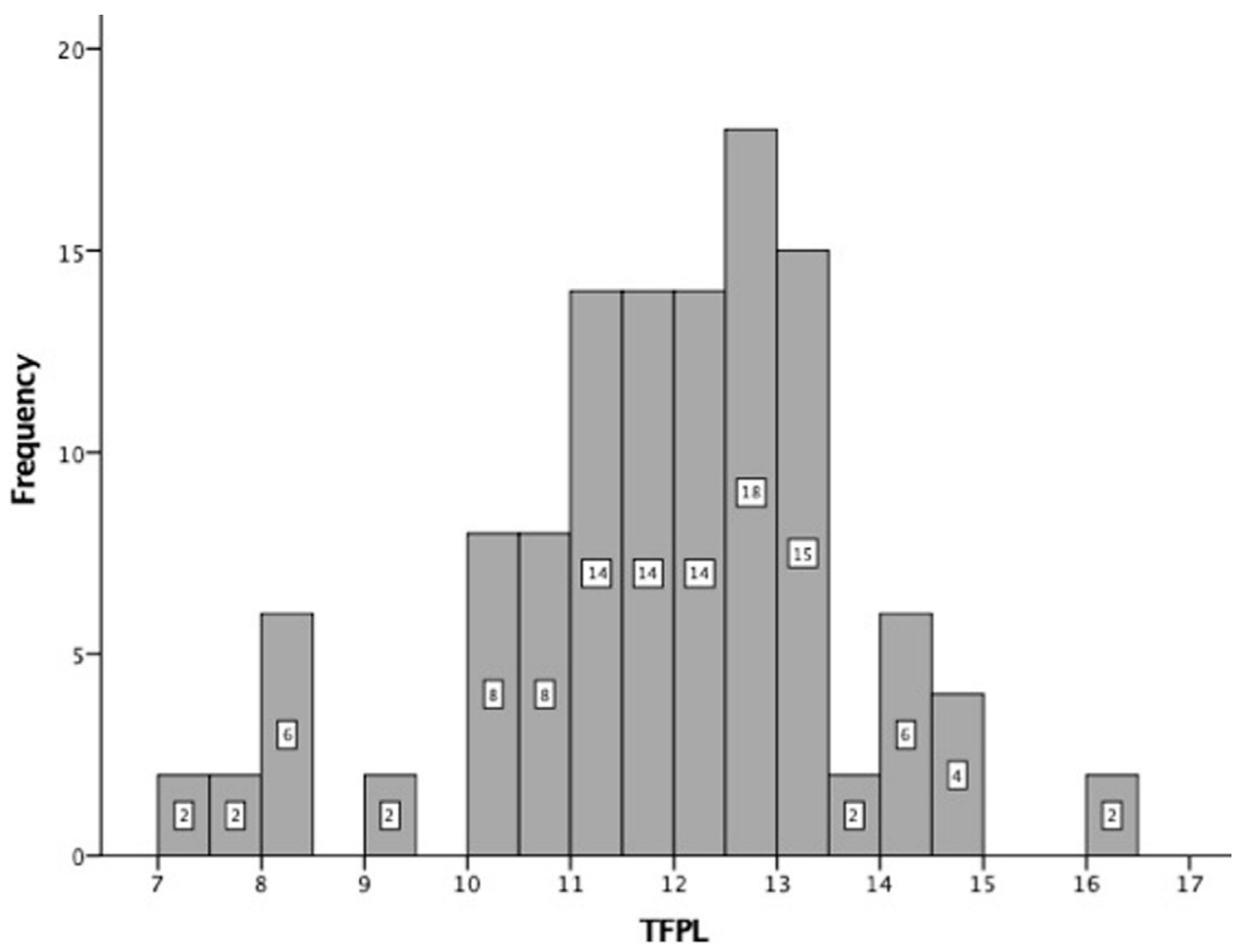




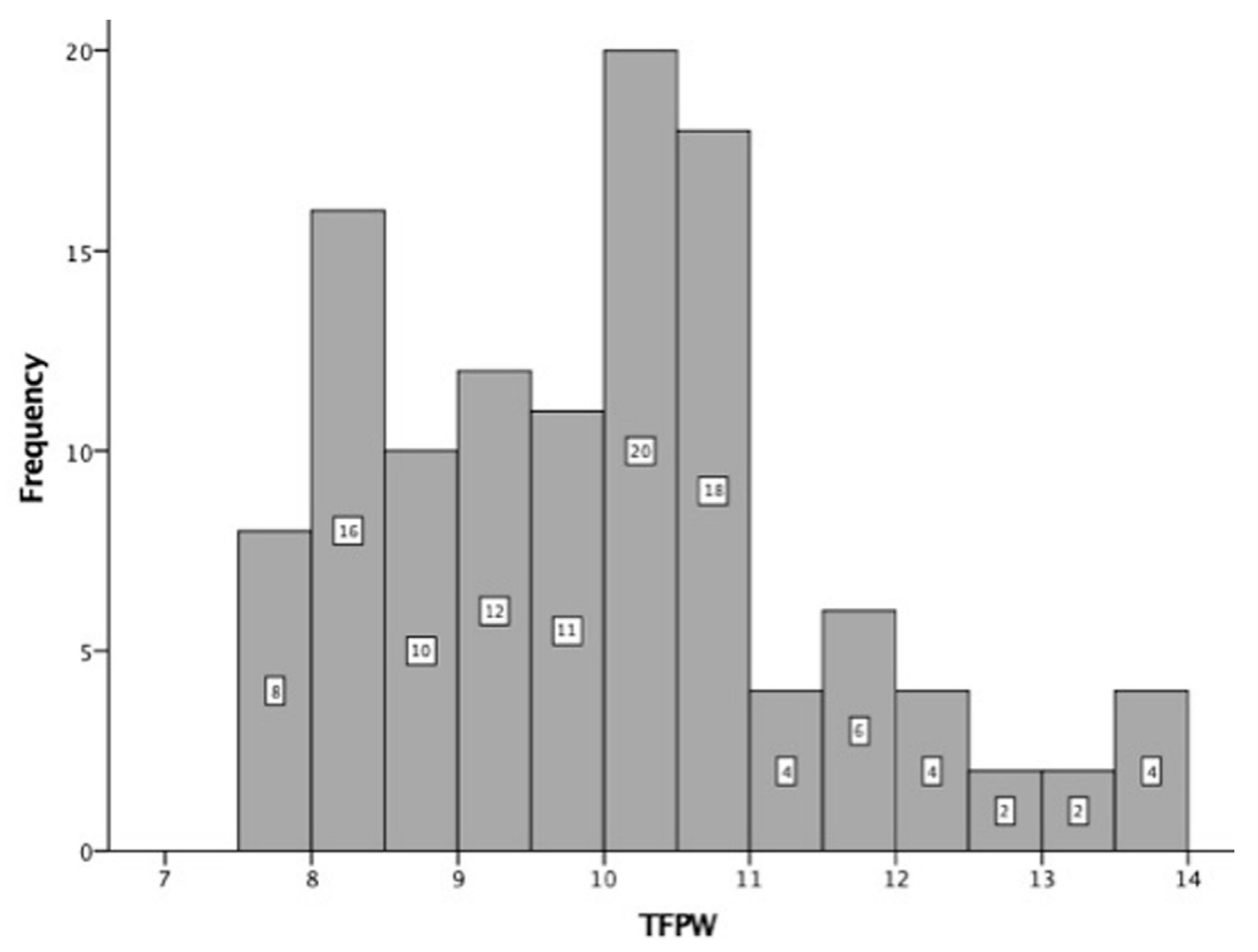

Fig 4. Distribution of anterior cruciate ligament tibial footprint width in the study population. Tibial footprint width of $10 \mathrm{~mm}, 8$ $\mathrm{mm}$, and $9 \mathrm{~mm}$, respectively, are the most common group width in the population. TFPW, tibial footprint width.

0.1 (range 150-180 cm), a mean weight of $75.2 \pm 17.3$ (49.5-132.2 kg), a mean BMI of $26.5 \pm 5.17$ (range, 18.6-23.2 $\left.\mathrm{kg} / \mathrm{m}^{2}\right)$. Height and weight were measured on the day of the MRI.

The physical characteristics of the patients are shown in Table 1, and for each characteristic, the values were significantly larger in males than in females. The average tibial footprint length and width of ACL were, respectively, $11.91 \pm 1.8 \mathrm{~mm}$ (range, 7.39-16.14) and $9.98 \pm 1.5 \mathrm{~mm}$ (range, 7.59-13.70). The mean tibial footprint length on the basis of sex was $12.4 \pm 1.5 \mathrm{~mm}$ (range, 9.04-16.04) for men and 10.9 $\pm 1.9 \mathrm{~mm}$ (range, 7.39-13.33) for women $(P<.0001)$. Tibial footprint width on the basis of sex was $10.4 \pm 1.4 \mathrm{~mm}$ (range, 7.66-13.70) for men and $9.1 \pm 1.3 \mathrm{~mm}$ (range, 7.5912.29) for women $(P<.0001)$.

In 105 knees $(89.7 \%)$ the length of ACL tibial footprint was $<14 \mathrm{~mm}$, and in 8 knees $(6.83 \%)$ the width of tibial footprint was $<8 \mathrm{~mm}$. The distributions of the

Table 2. Variables of Physical Characteristics Associated With ACL Tibial Footprint Length

\begin{tabular}{lccc}
\hline \multicolumn{1}{c}{ Variable } & $<14 \mathrm{~mm}(\mathrm{n}=105)$ & $\geq 14 \mathrm{~mm}(\mathrm{n}=12)$ & $P$ Value \\
\hline Age $($ year $)$ & $31.57 \pm 5.58$ & $32.00 \pm 6.98$ & .582 \\
Height $(\mathrm{cm})$ & $167.22 \pm 8.27$ & $175.50 \pm 5.21$ & .001 \\
Weight $(\mathrm{kg})$ & $72.87 \pm 15.11$ & $95.53 \pm 22.08$ & .001 \\
BMI $\left(\mathrm{kg} / \mathrm{m}^{2}\right)$ & $25.99 \pm 4.84$ & $30.83 \pm 6.13$ & .006
\end{tabular}

Data were given in mean \pm standard deviation.

ACL, anterior cruciate ligament; BMI, body mass index $\left(\mathrm{kg} / \mathrm{m}^{2}\right)$. length and width of the ACL tibial footprint are shown in Figs 3 and 4. The intraclass correlation coefficient for intraobserver reliability was 0.912 in length $(P<.001)$ and 0.871 in width $(P<.001)$.

The differences in the potential variables to predict the ACL tibial footprint length $>14 \mathrm{~mm}$ or $<14 \mathrm{~mm}$ are shown in Table 2. From all the physical characteristics, short height, lower body weight, and lower BMI were correlated with an increased possibility of tibial footprint length $<14 \mathrm{~mm}$. Between these variables, the strongest predictors were height (OR 0; 95\% CI 0- ) and weight (OR 3.052; 95\% CI 1.26$7.38)$; although they were conversely related to BMI (OR 0.044; 95\% CI 0.003-0.57). Multivariable logistic regression analysis, hence, showed height as the sole potential predictor of ACL tibial footprint length $>14$ $\mathrm{mm}$ or $<14 \mathrm{~mm}$ (Table 3). The cutoff value for tibial footprint length $<14 \mathrm{~mm}$, calculated by use of

Table 3. Variables of Physical Characteristics Associated With ACL Tibial Footprint Length

\begin{tabular}{llllll}
\hline & \multicolumn{2}{c}{ Univariable Analysis } & & \multicolumn{2}{c}{ Multivariable Analysis } \\
\cline { 2 - 3 } \multicolumn{1}{c}{ Variable } & \multicolumn{1}{c}{ Or $(95 \% \mathrm{CI})$} & $P$ Value & & Or $(95 \% \mathrm{CI})$ & $P$ Value \\
\hline Age $(\mathrm{yr})$ & $0.894(0.75-1.07)$ & .219 & & \\
Height $(\mathrm{cm})$ & $0.000(0-\sim)$ & .025 & & $0.000(0-\sim)$ & .004 \\
Weight $(\mathrm{kg})$ & $3.052(1.26-7.38)$ & .013 & & \\
BMI $\left(\mathrm{kg} / \mathrm{m}^{2}\right)$ & $0.044(0.003-0.57)$ & 0.044 & & \\
\hline
\end{tabular}

$\mathrm{ACL}$, anterior cruciate ligament; BMI, body mass index $\left(\mathrm{kg} / \mathrm{m}^{2}\right)$; $\mathrm{CI}$, confidence interval; OR, odds ratio. 
Table 4. Univariable and Multivariable Analyses for ACL Tibial Footprint Length

\begin{tabular}{lrr}
\hline & $\beta \pm \mathrm{SE}$ & $P$ Value \\
\hline Univariable analysis & & .499 \\
Age & $-0.019 \pm 0.029$ & $<.0001$ \\
Sex & $-1.503 \pm 0.319$ & $<.0001$ \\
Weight & $0.036 \pm 0.009$ & 0.004 \\
Height & $11.467 \pm 1.64$ & 0.162 \\
BMI & $0.03 \pm 0.032$ & 0.124 \\
Multivariable analysis for backward elimination & & 0.299 \\
Intercept & $-7.362 \pm 2.754$ & 0.008 \\
Height & $11.467 \pm 1.637$ & $0.293^{2}$ \\
\hline
\end{tabular}

ACL, anterior cruciate ligament; BMI, body mass index; MRI, magnetic resonance image.

*Adjusted $\mathrm{R}^{2}$.

standardized median for height, was $170 \mathrm{~cm}$ (89.7\%; 95\% CI).

Simple linear regression analysis indicated that the length of ACL tibia footprint showed correlation with sex $\left(\mathrm{R}^{2}=0.162, P<.0001\right)$, weight $\left(\mathrm{R}^{2}=0.124, P<\right.$ $.0001)$, and height $\left(\mathrm{R}^{2}=0.299, P<.0001\right)$ (Table 4$)$, whereas the width of ACL tibial footprint showed correlation with age $\left(\mathrm{R}^{2}=0.061, P<.007\right)$, sex $\left(\mathrm{R}^{2}=\right.$ $0.166, P<.0001)$, and height $\left(\mathrm{R}^{2}=0.125, P<.0001\right)$ (Table 5).

The following predictive equation was created through multiple regression analysis for ACL tibial footprint length based on height $=-7.362+11.48 \times$ height (meters) (adjusted $\mathrm{R}^{2}=0.293, P<.0001$ ). The predictive equation for ACL tibial footprint width was based on multiple regression analysis on the basis of age, sex, and BMI $=11.09+0.06 \times$ age (years) $1.37 \times$ sex $($ male $=1$, female $=2)-0.05 \times$ BMI $(\mathrm{kg} /$ $\mathrm{m}^{2}$ ) (adjusted $\mathrm{R}^{2}=0.223, P<.0001$ ).

\section{Discussion}

The most important finding of this study was that the patient's height can be used to predict ACL tibial footprint length. Good preoperative planning is pivotal in ensuring a successful ACL reconstruction. Measurement of tibial footprint sizes have been studied all over the world, but the results vary. ${ }^{7-11}$ Previous studies showed that the shape and size of the ACL tibial footprint differs among patients. ${ }^{13-15}$ Predictive equations for ACL tibial footprint length and width might serve as additional preoperative planning guides regarding surgical technique and graft options before ACL reconstruction.

This study demonstrated significant difference between male and female height, weight, and BMI, as well as their ACL tibial footprint length and width, which is in accordance with previous studies by Ichiba et al. ${ }^{6}$ and Kulkamthom et al. ${ }^{16}$ showing significantly larger sizes in male compared to female patients. Ichiba et al. ${ }^{6}$ evaluated the tibial fovea sizes of 100 knees from 50 males and 50 females using sagittal MRI and found that females were more likely to have fovea diameter $<13 \mathrm{~mm}$ rendering a special consideration on techniques and graft options before surgery.

The distribution of ACL tibial footprint sizes in this study was most similar to the study by Gali et al. ${ }^{11}$ who made measurements in 33 patients underwent total knee arthroplasty (TKA) showing average tibial fovea length of $11.7 \pm 2.0 \mathrm{~mm}$ and width of $7.1 \pm 1.4 \mathrm{~mm}$ compared to the mean length and width from our population $(11.91 \pm 1.8 \mathrm{~mm}$ and $10.9 \pm 1.9 \mathrm{~mm})$. Gali et al. ${ }^{11}$ also mentioned a strong correlation between

Table 5. Univariable and Multivariable Analyses for ACL Tibial Footprint Width

\begin{tabular}{lrr}
\hline & $\beta \pm \mathrm{SE}$ & $P$ Value \\
\hline Univariable analysis & & $\mathrm{R}^{2}$ \\
Age & $0.064 \pm 0.024$ & .007 \\
Sex & $-1.286 \pm 0.269$ & $<.0001$ \\
Weight & $0.012 \pm 0.008$ & .145 \\
Height & $6.265 \pm 1.546$ & $<.0001$ \\
BMI & $-0.10 \pm 0.027$ & .717 \\
Multivariable analysis for backward elimination & & 0.018 \\
Intercept & 11.086 & 0.125 \\
Age & $0.063 \pm 0.021$ & 0.001 \\
Sex & $-1.374 \pm 0.267$ & $0.223^{2}$ \\
BMI & $-0.049 \pm 0.024$ & \\
\hline
\end{tabular}

$\mathrm{ACL}$, anterior cruciate ligament; BMI, body mass index; MRI, magnetic resonance image.

*Adjusted $\mathrm{R}^{2}$. 
tibial width and height, which in our population showed a higher mean height ( $1.68 \pm 0.1 \mathrm{~m}$ compared to $1.59 \pm 0.08 \mathrm{~m}$ ), hence, showing a larger width. Our study also only included patients between 18 to 40 years, demonstrating a population with more ACL injuries.

More anatomic ACL reconstruction aims to functionally restore the ACL to its native dimension, collagen orientation, and insertion sites to try to reproduce normal anatomy, restore kinematics, and provide long-term joint health. ${ }^{17}$ In a double-bundle ACL reconstruction, it is important to avoid implanting grafts larger than the native ACL footprint, which will impede bone tendon healing and graft remodeling and result in impingement at the intercondylar notch and posterior cruciate ligament. ${ }^{4-6}$

This study population demonstrated a slightly lower result than other studies from other Asian populations. In a study by Park et al., ${ }^{9}$ who made the measurements in 127 patients underwent TKA showing average tibial insertion length of $13.8 \mathrm{~mm}(10.0-18.0 \mathrm{~mm})$ and width $9.8 \mathrm{~mm}(6.3-13.5 \mathrm{~mm})$ with $53.5 \%$ patients had length $<14 \mathrm{~mm}$. Our population showed a higher percentage of patients who had length $<14 \mathrm{~mm}(89.7 \%)$ probably because of a difference in technical measurements (radiologic versus direct). These data should be used as guidance for better preoperative planning.

Kim et al. ${ }^{8}$ compared 164 tibial footprint sizes that underwent direct measurement and found with MRI smaller sizes for tibial length of $12.4 \mathrm{~mm}$ (range, 9.7$15.3 \mathrm{~mm}$ ) versus its actual size of $13.8 \mathrm{~mm}$ (range 10.617.8) $(P<.0001)$ and larger sizes for tibial width of 8.8 $\mathrm{mm}$ (range, 7.0-12.1 mm) versus its actual size of 7.2 $\mathrm{mm}$ (range, 5.8-10.4 mm) $(P<.0001)$. This mismatch might be due to the unparalleled long axis of the ACL tibial footprint with the anteroposterior diameter of the ACL in the sagittal plane of MRI, and the width of the ACL tibial footprint was also not parallel to the mediolateral diameter of the ACL in the coronal plane of MRI. ${ }^{9}$ However, their study showed that MRI measurements of ACL tibial footprint strongly correlate with its actual sizes. ${ }^{8}$

In the western study population Guenther et al. ${ }^{13}$ showed on MRI an even larger size of tibial insertion length of $16.6 \pm 1.3 \mathrm{~mm}$ but a similar width of $10.2 \pm$ $1.0 \mathrm{~mm}$. In almost all of the previous studies, tibial footprint length was positively correlated with weight and height or height alone of the patients. ${ }^{6,9-11,13} \mathrm{~A}$ bigger size of tibial length in the western population might be due to the higher mean height in the western population compared to ours such as the mean height in Guenther's study of $174.3 \pm 10.1$ versus $168.07 \pm$ $0.1 .^{13}$

Direct measurements performed in elderly patients undergoing TKA had a different population compared to the common populations suffered from ACL injury.
Although the footprint size might be intact, but some degenerative changes might compromise the measurements. Hence, our study better represents a population of patients having the ACL injuries, which makes this the reason for our inclusion criteria.

\section{Limitation of Study}

This study does have limitations. First, larger samples might be required to create a stronger correlation prediction. The adjusted $\mathrm{R}^{2}$ we obtained from the measurement was 0.293 showing a weak predictive equation between the MRI sizes and anthropometric data. Second, measurement of other anthropometric data such as leg length, femoral length, and tibial length might be included to enhance prediction equation as demonstrated by Park et al. ${ }^{9}$ Last, we conduct the population on the basis of our population, which is mostly Asian, whereas other studies previously showed variable results from different populations..$^{8-11,13}$

\section{Conclusion}

The height of the patients may predict the length of the ACL tibial footprint. Although patient's age, sex, and BMI correlate poorly with ACL tibial footprint width, there are no correlations between patient's weight and ACL tibial footprint size.

\section{References}

1. Fu FH, van Eck CF, Tashman S, Irrgang JJ, Moreland MS. Anatomic anterior cruciate ligament reconstruction: A changing paradigm. Knee Surg Sports Traumatol Arthrosc 2015;23:640-648.

2. Bjornsson H, Desai N, Musahl V, et al. Is double-bundle anterior cruciate ligament reconstruction superior to single-bundle? A comprehensive systematic review. Knee Surg Sports Traumatol Arthrosc 2015;23:696-739.

3. Oh JY, Kim KT, Park YJ, et al. Biomechanical comparison of single-bundle versus double-bundle anterior cruciate ligament reconstruction: A meta-analysis. Knee Surg Sports Traumatol Arthrosc 2020;32:14.

4. Lehmann AK, Osada N, Zantop T, Raschke MJ, Petersen W. Femoral bridge stability in double-bundle ACL reconstruction: impact of bridge width and different fixation techniques on the structural properties of the graft/femur complex. Arch Orthop Trauma Surg 2009;129:1127-1132.

5. Chiang ER, Chen KH, Lin ACC, Chang MC, Liu CL, Chen TH. Comparison of tunnel enlargement and clinical outcome between bioabsorbable interference screws and cortical button-post fixation in arthroscopic doublebundle anterior cruciate ligament reconstruction: A prospective, randomized study with a minimum follow up of 2 years. Arthroscopy 2019;35:544-551.

6. Ichiba A, Kido H, Tokuyama F, Makuya K, Oda K. Sagittal view of the tibial attachment of anterior cruciate ligament on magnetic resonance imaging and the relationship between anterior cruciate ligament size and the physical characteristics of patients. J Orthop Sci 2014;19:97-103. 
7. Kopf S, Pombo MW, Szczodry M, Irrang JJ, Fu FH. Size variability of the human anterior cruciate ligament insertion site. Am J Sports Med 201 1;39:108-113.

8. Kim SH, Lee HJ, Park YB, Jeong HS, Ha CW. Anterior cruciate ligament tibial footprint size as measured on magnetic resonance imaging: Does it reliably predict actual size? Am J Sports Med 2018;46:1877-1884.

9. Park YB, Song YS, Kim SC, Park YG, Ha CW. The size of tibial footprint of anterior cruciate ligament and association with physical characteristics in Asian females. Arch Orthop Trauma Surg 2015;135:985-992.

10. Park YB, Ha CW, Kim HJ, Park YG. Preoperative prediction of anterior cruciate ligament tibial footprint size by anthropometric variables. Knee Surg Sports Traumatol Arthrosc 2017;25:163811645.

11. Gali JC, Giglio DBD, Patriarcha LF, Cruz BAP, Filho JCG. Rev Bras Orthop 2020;55:88-94.

12. Araujo P, van Eck CF, Torabi M, Fu FH. How to optimize the use of MRI in anatomic ACL reconstruction. Knee Surg Sports Traumatol Arthrosc 2013;21:1495-1501.
13. Guenther D, Irarrázaval S, Albers M, et al. Area of the tibial insertion site of the anterior cruciate ligament as a predictor for graft size. Knee Surg Sports Traumatol Arthrosc 2017;25:1576-1582.

14. Guenther D, Irarrazaval S, Nishizawa Y, et al. Variation in the shape of the tibial insertion site of the anterior cruciate ligament: classification is required. Knee Surg Sports Traumatol Arthrosc 2017;25:2428-2432.

15. Tashiro Y, Lucidi GA, Gale T, et al. Anterior cruciate ligament tibial insertion site is elliptical or triangular shaped in healthy young adults: high-resolution 3-T MRI analysis. Knee Surg Sports Traumatol Arthrosc 2018;26:485-490.

16. Kulkamthom N, Arkasihayuth A, Charakorn K, Chaimut M, Reeboonlap N. The study of anterior cruciate ligament footprint in Thai population: a human cadaveric study. J Med Assoc Thai 2012;95:S167-S172 (Suppl 10).

17. van Eck CF, Lesniak BP, Schreiber VM, Fu FH. Anatomic single- and double bundle anterior cruciate ligament reconstruction flowchart. Arthroscopy 2010;26:258-268. 